\title{
The Application of Computer and Its Influence in Coal Quality Testing LUO Yugang ${ }^{\star 1, a}$, WANG Yuli, ${ }^{2, b}$ \\ ${ }^{1}$ Guizhou Agency of Quality Supervision and Inspection of Coal Product, Liupanshui city 553001, China \\ aluoyugang@163.com, bwangyuli@126.com
}

Keywords: Image Recognition, Database Management, Coal Quality Detection

\begin{abstract}
With the rapid development of our country's economy, modern society has entered the information age. Computer technology, communication technology and the development of computer network technology, automated information processing ability and level enhances unceasingly, information technology in all fields of people's social activities and life has been widely applied. Coal quality is directly related to the economic benefits of power plant, so must find a quick and effective detection methods of coal quality checks. Coal quality inspection including the application of computer technology and the testing data database management from two aspects, in this paper, the current coal testing, sampling process applied to computer technology was studied systematically.
\end{abstract}

\section{Introduction}

In recent years, the domestic advanced mines, coal preparation plant, power plant to carry out the coal quality management network, using the modern communication and network technology, set up a high sensitive, quick response and reliable operation of information system, timely grasp the dynamic of coal, improve the quality of supervision and management informatization level and work efficiency [1]. Coal-fired power plants are from production to the benefit and cost as the core of market-oriented enterprise transformation, to reduce the cost, change inferior coal burning or mixed coal blending has become more and more power plants priority issues. The quality stability and diversity of fuel resources can also affect the pulverizing system and the safety of the boiler combustion, is directly related to the safe and economic operation of power plant. To ensure and control the quality of fuel coal blending, for effective monitoring of the whole combustion process in order to determine the mixed coal on combustion efficiency and the influence of pollutants discharge. Therefore, the coal quality testing is indispensable steps in the process of modern coal-fired power generation, directly affects the production efficiency, production cost and production safety [2].

As the growth of the production of coal preparation plant and outbound task, increasingly heavy coal quality supervision and management work, is to speed up the coal equipment introduction and technical updates, but is still in the stage of extensive management, has been difficult to meet the needs of new situation, it is imperative to promoting coal quality management informatization. New coal quality management network is to use the computer network system as the main body of the digital, networked, intelligent, visualization means of modern technology, using the co-construction and sharing mechanism, around the concept of people-oriented, the coal test data, information and so on carries on the strategic reorganization of network resources and construction, establish a rational layout, complete functions, efficiency of coal quality information sharing platform, strengthening the scientific data sharing, raise the utilization rate of resources, improve coal quality management level of the whole.

\section{Coal quality testing job analysis}

Coal quality testing is through real-time monitoring and gathering including on-line ash measuring meter, heat quantity meter series, sulfur meter series, the series of industrial analysis, etc., to provide quality analysis seamless data interface; And for safeguarding the smooth progress of the 
experiment of various resources, such as personnel, instrument, equipment, etc. into the effective management, improve the management level of laboratory, make the enterprise testing information level on a new step [3].

Selected for coal quality testing must be strictly implemented the standard method, if there is deviation, must be identified, and after technical judgment, laboratory authorization and customer accept. Any deviation should be documents shall be stipulated in the permit. Coal quality on-line detection technology in the field of coal industry analysis, the current international popular online analysis technology, it basically has the following kinds: microwave technology online measuring moisture; Dual-energy X-ray attenuation technique on-line measuring ash content; Neutron induced transient emission line technology to detect ash and carbon, hydrogen, oxygen and other elements; The fast neutron activation technique (PGNAA) detection of ash and ash composition and sulfur content. Usually the PGNAA technology combined with a water meter, still can determine the moisture content and calorific value index [4]. Coal quality detection system frame as shown in figure 1.

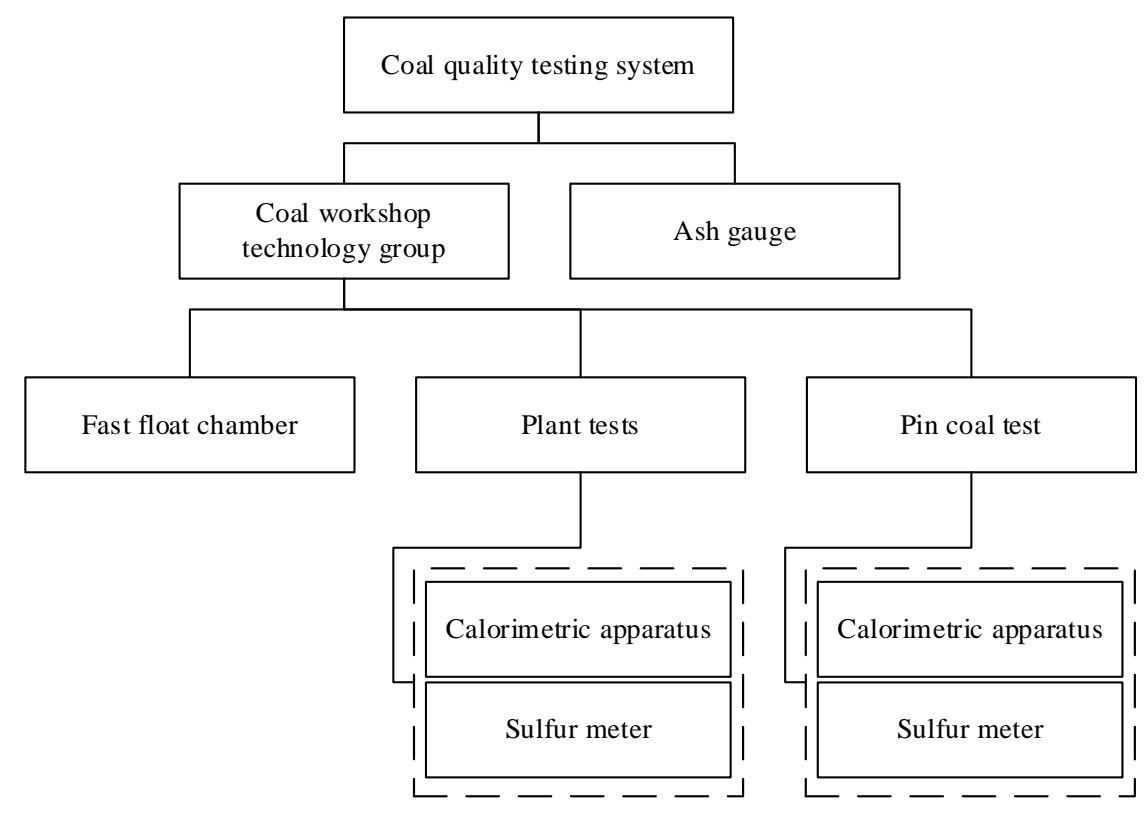

Figure 1.The overall frame of coal quality detection system

Fast float chamber computer lab monitor computer centered server (database server) an internal LAN, testing machine will according to the original test data acquisition, analysis, processing, printing; After the local area network (LAN) uploaded to the laboratory monitor computer server, collecting and processing; Each user can make its designated jurisdictions through WEB page (WEB server) for a variety of testing data results query. Furthermore, it provides external data interface, can be under the precondition of authorization data import plant-level dedicated database information management system, so that each user data query by plant-level information management system for test [5].

\section{Computer image processing technology in coal quality testing}

In the case of a power plant of coal demand, it is particularly important to control coal, using image processing technology, automatic identification area, can work efficiently and accurately sampling, the basic process is shown in figure 2 .

For the purpose of image processing is to identify the edge of the carriage, contour extraction is required for this purpose. Check the near each pixel edge detection operator to determine the gray level change of slope and direction, there are many edge detection operator, are based on convolution series of directional derivative template. Roberts operator, Sobel operator, Prewitt operator and Kirsch operator. In most cases, the image grayscale or average gray level of target region and background region, according to the uniformity of gray, gray subset of the target area 
can be determined, if the shade of grey value belongs to the point at which a subset of the can determine that point within the goal area. To determine whether a point located on the boundary of the target area and boundary strength should first find out the point, then point boundary strength compared with the a predetermined threshold, if the boundary point strength is greater than the threshold, can be set which is located in the boundary of the target area.

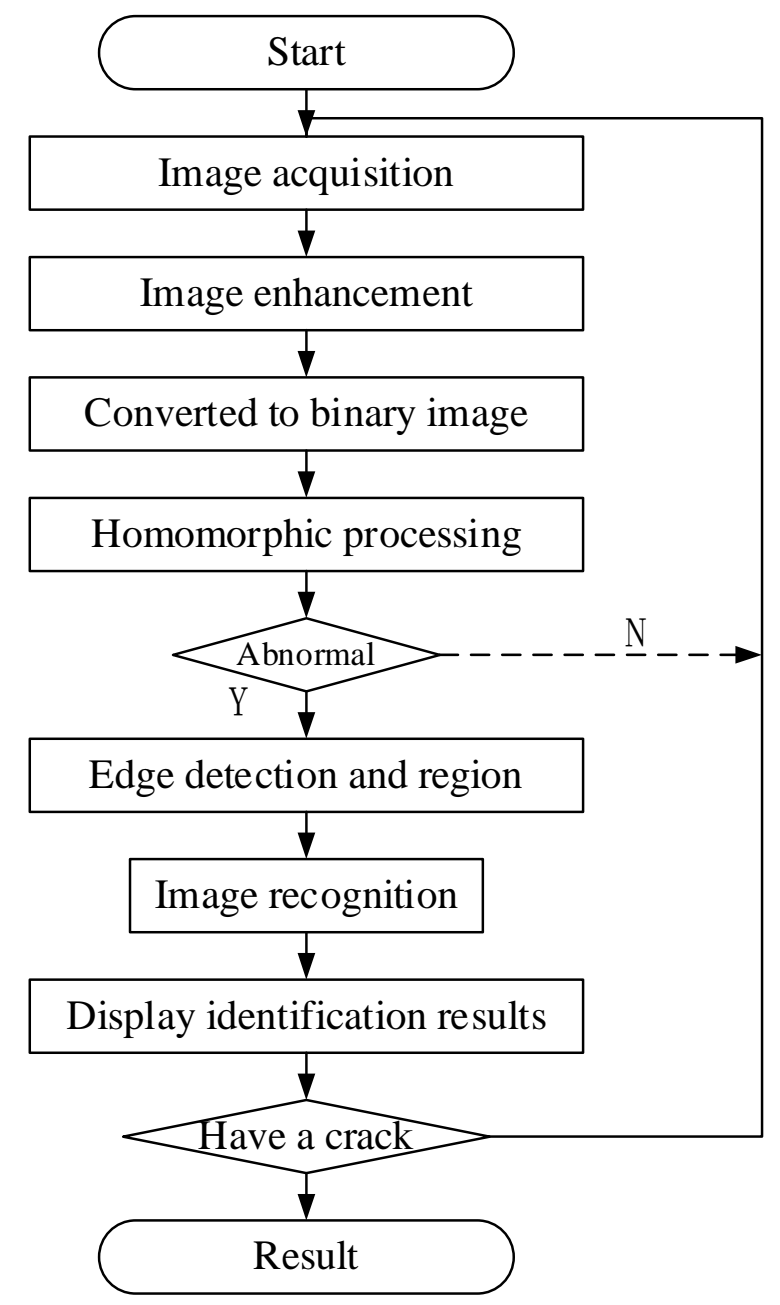

Figure 2.The basic process of computer image processing technology

\section{Computer database management technology in coal quality detection}

In addition to the computer image processing technology, but also can be combined with database technology, more easily to the history of information management and analysis in depth. The current coal quality detection of electronic management in general can be divided into three levels:

(1) Management of electronic documents and electronic form, is a kind of data management function.

(2) The stand-alone database management, realize the basic management functions of the data, but the data of the operation is simple, query, analysis, data sharing ability is not strong, has great limitations.

(3) The network data management, has realized the multi-user operating and data centralized management, has the strong ability of historical data query analysis.

New development of various management systems are basically based on network database of $\mathrm{C} / \mathrm{S}$ or $\mathrm{B} / \mathrm{S}$ system, in addition to realize the daily data of coal quality and coal quality testing unit equipment in all kinds of management, but also for all the detection of coal quality data for quality tracking, will all the test results and the coal storage information associated with shunt; Establish effective open data sharing system, can the comprehensive analysis of different quality inspection unit of the coal quality, track and analyze related coal of coal quality changes in the whole process 
of coal transportation, supervise related quality inspection unit test results found quality problems in time, realize the whole process of dynamic management and real-time management of coal quality. Coal quality detection in computer database management process is shown in figure 3.

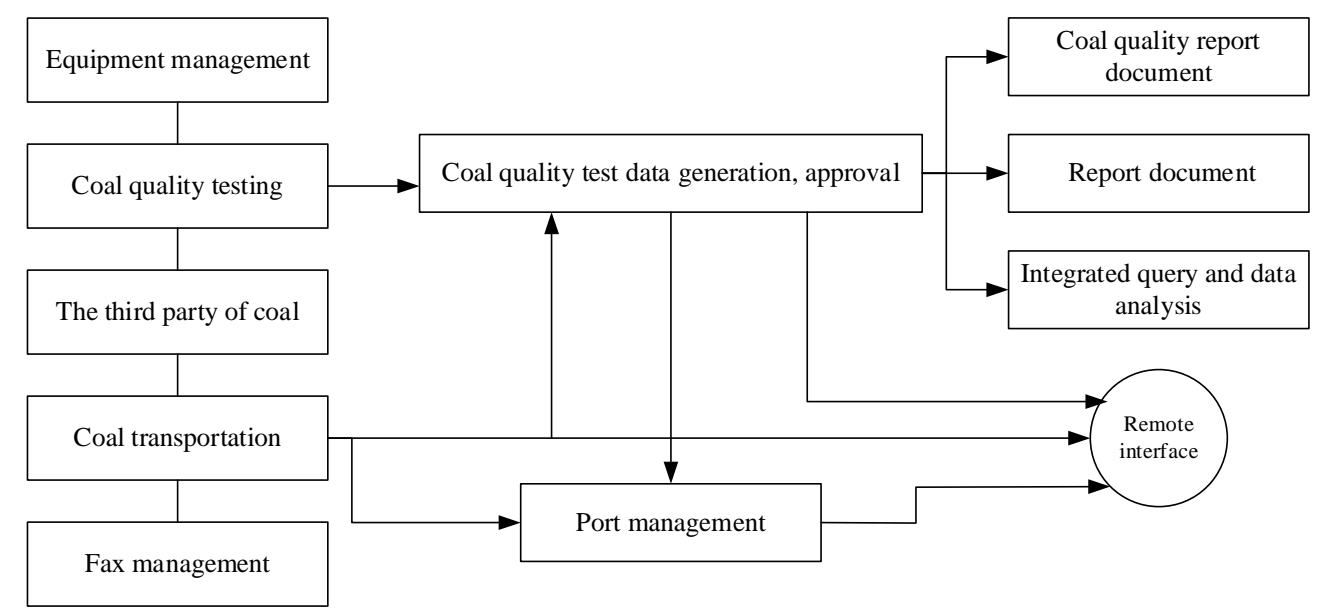

Figure 3.The basic process of coal quality detection in computer database management

\section{Conclusion}

Coal quality testing is indispensable in the process of power generation in modern power link, directly affects the production efficiency, production cost and the efficiency and quality of production safety to improve coal quality testing is to reform the management system, build the advanced, scientific, perfect operation mechanism, but also focus on thermal power technology development in the field of international tendency, while encouraging independent innovation, always USES the advanced science and technology. In the long run, in order to save coal resources, improve the boiler combustion efficiency and reduce power generation cost, to strengthen the coal quality supervision and coal quality detection using computer network system as the main body of the digital, networked, intelligent, visualization means of modern technology, using the co-construction and sharing mechanism, establish a rational layout, complete functions, efficiency has great significance to the coal quality information sharing platform, can significantly improve the overall level of coal quality management information.

\section{Reference}

[1] S.C. Chelgani, S. Mesroghli, and J.C. Hower: International Journal of Coal Geology, Vol.83(2010) No.1, p. 31.

[2] T. Lu, H. Yu, and T. Zhou: International Journal of Coal Geology, Vol.79(2009) No.1, p. 40.

[3] I. Hilber, F. Blum, J. Leifeld: Journal of agricultural and food chemistry, Vol.60(2012) No.12, p. 3042.

[4] H. Liu: Energy \& Fuels, Vol.23(2009) No.9, p. 4278.

[5] R.P. Singh, A.K. Gupta, M.H. Ibrahim: Reviews in Environmental Science and Bio/Technology, Vol.9(2010) No.4, p. 345. 